\title{
High levels of DDT in breast milk: Intake, risk, lactation duration, and involvement of gender
}

\author{
Hindrik Bouwman, Henrik Kylin, Barbara Sereda and Riana Bornman
}

\section{Linköping University Post Print}

N.B.: When citing this work, cite the original article.

Original Publication:

Hindrik Bouwman, Henrik Kylin, Barbara Sereda and Riana Bornman, High levels of DDT in breast milk: Intake, risk, lactation duration, and involvement of gender, 2012, Environmental Pollution, (170), , 63-70.

http://dx.doi.org/10.1016/j.envpol.2012.06.009

Copyright: Elsevier

http://www.elsevier.com/

Postprint available at: Linköping University Electronic Press

http://urn.kb.se/resolve?urn=urn:nbn:se:liu:diva-84879 


\title{
High levels of DDT in breast milk: Intake, risk, lactation duration, and involvement of gender
}

\author{
Hindrik Bouwman $^{\mathrm{a}, *}$, Henrik Kylin ${ }^{\mathrm{b}, \mathrm{c}}$, Barbara Sereda ${ }^{\mathrm{d}}$, Riana Bornman ${ }^{\mathrm{e}}$ \\ ${ }^{\text {a }}$ School of Environmental Sciences and Development, North-West University, \\ Potchefstroom, 2520, South Africa \\ ${ }^{\mathrm{b}}$ Department of Water and Environmental Studies, Linköping University, Linköping, Sweden \\ c Norwegian Institute of Air Research, Fram Centre, Tromsø, Norway \\ ${ }^{d}$ Plant Protection Research Institute, Agricultural Research Council, Pretoria, South Africa \\ e Department of Urology, University of Pretoria, Pretoria, South Africa
}

*Corresponding author:

H Bouwman

School of Environmental Sciences and Development

North-West University

P. Bag X6001

Potchefstroom 2520

South Africa

Tel: +27 182992377

Fax: +27 182992503

henk.bouwman@nwu.ac.za

\begin{abstract}
We investigated presence and levels of DDT in 163 breast milk samples from four South African villages where, in three of them, malaria is controlled with DDT sprayed indoors. Mean $\Sigma$ DDT levels in breast milk were 18, 11, and $9.5 \mathrm{mg} / \mathrm{kg} \mathrm{mf}$ (milk fat) from the three DDT-sprayed villages, respectively, including the highest $\Sigma$ DDT level ever reported for breast milk from South Africa (140 mg/kg mf). Understanding the causes for these differences would be informative for exposure reduction intervention. The Provisional Tolerable Daily Intake (PTDI) for DDT by infants, and the Maximum Residue Limit (MRL) were significantly exceeded. DDT had no effect on duration of lactation. There were indications (not significant) from DDT-sprayed villages that first-born female infants drink milk with more $\Sigma$ DDT than first-born male infants, and vice versa for multipara male and female infants, suggesting gender involvement on levels of DDT in breast milk - requiring further investigation.
\end{abstract}

Keywords: Breast milk; South Africa; malaria control; indoor residual spray; maximum residue level; provisional tolerable daily intake. 


\section{Introduction}

DDT (dichlorodiphenyltrichloroethane) in humans continues to draw much attention, primarily due to legacy issues (e.g. Cao et al., 2011; Cohn, 2011; Fromberg et al., 2011; Glynn et al., 2011) and its continued use in malaria vector control (Eskenazi et al., 2009; van den Berg, 2009; Darnerud et al., 2010; Bouwman et al., 2011). The problems with the use of DDT stems largely from its persistence, bioaccumulation, toxicity, and physical-chemical capacity for long-range transport (Mackay et al, 2006; Stockholm Convention, 2012).

The World Health Organization (WHO) estimated that 174 million cases of malaria occurred in 2010 (81\% in Africa). An estimated 655000 died from malaria (91\% in Africa); $86 \%$ were children under the age of 5 (WHO, 2011b). Reducing malarial morbidity and mortality remains a high priority. About 4.1 million people are at risk of malaria in South Africa and are protected by yearly IRS with DDT and pyrethroids. DDT is applied an as indoor residual spray (IRS) at $2 \mathrm{~g} / \mathrm{m}^{2}$ on indoor walls, rafters, and elsewhere by trained provincial applicators. Between 64 and $128 \mathrm{~g}$ of DDT is applied per average dwelling, entering the human body via food, dermal exposure, and air (Van Dyk et al., 2010). In 2009, $63750 \mathrm{~kg}$ of DDT was applied in South Africa.

The presence of lipophilic DDT in human breast milk has been known for more than 60 years (Laug et al., 1951). In malaria areas, DDT levels in breast milk generally exceed the maximum residue limit (MRL, for bovine milk), and DDT intake by infants exceeds the provisional tolerable daily intake (PTDI) significantly (Bouwman et al., 2006; Okonkwo et al., 2008). The recently released WHO health risk assessment on DDT as used in IRS (WHO, 2011a) concluded that.... "in some areas, the exposures in treated residences have been higher than potential levels of concern. Efforts are needed to implement best practices to protect residents in treated households from exposures arising from IRS. Of particular concern would be women of childbearing age who live in DDT IRS-treated dwellings and transfer of DDT and DDE to the foetus in pregnancy and to the infant via lactation." However, other than stating that exposures should be reduced, the health implications of exceedances were not addressed. The paradox inherent in combating a deadly disease with a compound that is increasingly associated with a number of human health conditions remains a difficult and vexing issue (Bouwman et al., 2011).

Parity and infant age are well-known factors that govern levels of DDT in human milk (Bouwman et al., 1990b; Mishra and Sharma, 2011). A factor less often explored is location (Cerna et al., 2010; Mishra and Sharma, 2011). IRS in SA is a provincial responsibility, with three separate provincially operated spraying programmes in Mpumalanga, Limpopo, and KwaZulu-Natal (Fig. 1). Although all three operate according to WHO IRS guidelines (WHO, 2007), operational and cultural differences between provinces might be sufficient to influence DDT levels in breast milk. Although levels of DDT in breast milk are known from two of the three provinces - KwaZulu-Natal (Bouwman et al., 1990a) and Limpopo (Okonkwo et al., 2008) - no study has yet used the same collection and analytical procedures in different provinces.

DDT might reduce (Rogan and Gladen, 1985; Rogan et al., 1987; Gladen and Rogan, 1995; Kostyniak et al., 1999), lengthen (Weldon et al., 2006) or have no effect (Cupul-Uicab et al., 2008) on duration of lactation, due to the endocrine disruptive properties of DDT isomers and breakdown products (Wetterauer et al., 2012). The levels of DDT in SA are exceedingly high - the highest yet measured was $59.3 \mathrm{mg} / \mathrm{kg} \Sigma \mathrm{DDT} \mathrm{mf}$ (milk fat) (Bouwman et al., 1990a). From a DDT-sprayed area in Zimbabwe, Chikuni et al. (1991) reported a maximum $\Sigma$ DDT of $102 \mathrm{mg} / \mathrm{kg} \mathrm{mf}$. Determining the possible effect of DDT on duration of lactation from a high-exposure situation would therefore be very informative. 
First-born infants receive much higher levels of DDT in breast milk than their sibs (Harris et al., 2001; Bouwman et al., 2006). Recently however, the differences in pollutant levels and effects between male and female infants received attention (Ribas-Fitó et al., 2006; Jusko et al., 2006; Grimalt et al., 2010; Jackson et al., 2010; Gascon et al., 2011). This implies that infant gender may somehow influence levels of pollutants in breast milk. One gender receiving higher levels than the other would add to concern about possible effects of DDT on urogenital development due or the known endocrine disruptive properties of DDT pollutants, a situation already suspected in South Africa (Bornman et al., 2010).

With the aim of investigating exposure, we report and compare levels and patterns of DDT in breast milk from three DDT-sprayed villages and one reference village from two provinces in South Africa, examine factors that influence these, and discuss risk. We also report on the possibility that DDT may affect the duration of lactation, and if male and female infants experience different exposures via breast milk.

\section{Materials and methods}

\subsection{Sample collection}

Fig. 1 indicates the location of the villages. Dididi in Limpopo, and Manguzi and Mseleni in KwaZulu-Natal have been under IRS treatment since the 1950s, with interruptions in KwaZulu-Natal between 1996 and 2000 when pyrethroids were applied. These three villages are called 'DDT-sprayed villages' throughout. Gwaliweni was the 'reference village', with no malaria, and has never been sprayed. More information on the social and economic conditions in KwaZulu-Natal (Bouwman et al., 2006; Sereda et al., 2009) and Limpopo (Van Dyk et al., 2010) are available. In KwaZulu-Natal, Manguzi was DDTsprayed between 10-12 July 2007, and Mseleni on 1 August 2007. In Limpopo, Dididi was treated between 23 November and 14 December 2007. Breast milk collections were done in February 2008. Ethical approval was obtained from the respective provincial departments of health of Limpopo and KwaZulu-Natal, Pharma-Ethics, and the ethics committee of the University of Pretoria. All collections were done with informed consent in the local language by trained personnel and recorded. Only mothers born in areas with IRS were selected for the DDT-sprayed villages, and only mothers not born in DDT-sprayed villages for the reference village. Mothers were asked to initiate breast-feeding their infants so as not to collect foremilk. Mothers then manually expressed $25 \mathrm{ml}$ directly into cleaned glass jars; the jars were capped immediately, stored on ice, and frozen on the same day.

Analyses were done at the Plant Protection Research Institute of the Agricultural Research Council (ARC). Before analyses, the milk was thawed, vigorously shaken, and aliquots taken. All glassware was thoroughly cleaned, and all solvents were high purity. Milk fat was determined gravimetrically. The QuEChERS- A mini-multi-residue method for the analysis of pesticides residues in low-fat products was done for $5 \mathrm{ml}$ samples with a final extract volume of $200 \mu \mathrm{l}$, with a $1 \mu \mathrm{l}$ injection volume. The calibration curve standards, blank matrix, QA and all the samples were extracted and analyzed in exactly the same manner. Analyses were done on an Agilent 6890N gas chromatograph with a 5975 inert massselective detector (MSD) in the select-ion monitoring mode. A multi-point calibration curve was prepared with matrix-matched standards containing the analytes of interest. After injection of single standards and confirmation with the NIST 05 Spectral Library, a target ion (235 for the DDTs and DDDs, and 245 for the DDEs) and two qualifier ions (237 and 165 for the DDTs and DDDs, and 248 and 318 for the DDEs) were identified from the full spectra of each analyte. Identification was done based on retention times, presence of the target ion and two qualifier ions. The qualifier ion/target ion abundance ratio of the samples was detected 
within $20 \%$ of matrix matched standards target ion ratios. The target ion was used for quantification. Recoveries ranged between 70 and $120 \%$ and results were corrected for recovery. Due to interfering peaks, only p,p'-DDT, p,p'-DDE, p,p'-DDD and o,p'-DDT were quantified. Limits of quantification were $10 \mu \mathrm{g} / \mathrm{kg}$ mf but matrix effects allowed some lower values to be measured. Work was done based on Good Laboratory Practice principles and was audited by the ARC.

\subsection{Statistics}

Data are presented based on both whole milk (wm) and milk fat (mf) due to the large differences in milk fat content between samples (1.08-8.57\% - Table 1), and for reasons explained in Bouwman et al. (2006). Daily intake was calculated as $800 \mathrm{ml}$ by a $5 \mathrm{~kg}$ baby (Bouwman et al., 2006). Mean days breastfed per infant (MDBFI) is the mean of the number of days each mother reported for completed breastfeeding episodes. Cumulative days breastfed (CDBF) is the sum of all previous and current breastfeeding episodes - for primipara mothers, this is equivalent to the age of the infant. Where data was not normally distributed (e.g. concentrations), log-transformation was applied. Only values above quantification limits were used. All t-tests were unpaired and two-tailed, and differences in one-way ANOVA was tested with Bonferroni multiple comparison tests. Significance in all cases is $\mathrm{p}<0.05$.

\section{Results}

\subsection{Maternal and infant parameters}

None of the 163 mothers were accidentally or occupationally exposed to pesticides other than working on lands or through malaria control. Domestic and home-garden pest control was small scale only, mainly using formulated dusts or spray cans containing mostly pyrethroids. IRS with DDT was the only use of DDT in all DDT-sprayed villages. Table 1 presents the results per village (in the first column), and stratified for primiparae and multiparae. There were no significant differences in the mean ages of primipara mothers, multipara mothers, or infant ages between villages. The differences in mean ages between primipara and multipara mothers were significant within each village - about ten years for the DDT-sprayed villages and six years for Gwaliweni (ANOVA). There were no differences in percentage milk fat (\%mf) between parities and villages. The mean parities for the villages ranged between 2.0 - 2.2 with no significant differences.

\subsection{Effect of location}

Overall mean $\Sigma$ DDT in breast milk from all the DDT-sprayed villages were significantly higher than Gwaliweni (first column, Table 1). $\Sigma$ DDT from Manguzi was significantly higher than Mseleni, but not Dididi ( $<<0.05$, ANOVA). Within each DDTsprayed village, primipara milk had significantly higher p,p'-DDT, p,p'-DDE, p,p'-DDD and o,p'-DDT levels than multipara milk (t-tests). For primipara and multipara milk, the DDTsprayed villages had significantly higher p,p'-DDT, p,p'-DDE, p,p'-DDD and o,p'-DDT levels than Gwaliweni. \%DDT (percentage of p,p'-DDT of $\Sigma$ DDT) in milk from primipara mothers from DDT-sprayed villages did not differ between villages. However, \%DDT in Manguzi multipara milk was significantly higher than multipara milk from the other two villages (ANOVA). 


\subsection{Exposure and risk}

Fig. 2A shows levels of $\Sigma$ DDT in whole milk stratified according to village and parity. The mean $\Sigma$ DDT levels in milk from the DDT-sprayed villages and primipara milk from the reference village significantly exceeded the $\Sigma$ DDT MRL of $20 \mu \mathrm{g} / \mathrm{l} \mathrm{wm}$ (FAO \& WHO, 2005). Fig. 2B shows the same categories for daily intake by infants. The PTDI for $\Sigma$ DDT is $10 \mu \mathrm{g} / \mathrm{kg} /$ day (FAO \& WHO, 2005). Infant intakes in all DDT-sprayed villages significantly exceeded the PTDI (one-sample t-tests). The intake by primipara infants from the reference village was not different from the PTDI, but multipara PTDI for the reference village was significantly less (one-sample t-tests).

\subsection{Duration of lactation}

For mothers that have completed breastfeeding at least one infant, the mean days breastfed per infant (MDBFI) ranged between 30-1440 days, with means per village between 554-681 (Table 1 and Fig. 2C). The curious pattern shown by the scatter plot is due to mothers recalling approximate months with clustering around 12, 18 and 24 months. However, as all mothers were interviewed for the same information in the same way, the data is considered comparable between villages. There were no significant differences in MDBFI between villages ( $p=0.0912$, ANOVA). Fig. 2D plots $\Sigma$ DDT against the cumulative days breastfed (CDBF). Although a non-linear regression would be complicated by mothers accumulating DDT between breast feeding episodes, a one-phase decay of $\Sigma$ DDT is shown with $\mathrm{R}^{2}=0.126$, a half-life of 287 days, and a plateau at $7100 \mu \mathrm{g} / \mathrm{kg} \mathrm{mf}$.

\subsection{Infant gender and levels of DDT}

Since infants drink whole milk, and MRL s and PTDIs are based on whole milk, possible differences in intake between genders were calculated on a whole milk basis.

Combining the $\Sigma$ DDT levels in milk consumed by the multipara male and female babies from the three DDT-sprayed villages and comparing their means provided a p-value of 0.0540 (ttest). Fig. $2 \mathrm{E}$ shows the $\Sigma \mathrm{DDT}$ levels in primipara whole milk stratified according to male and female infants. In two of the DDT-sprayed villages, primipara female babies received milk with higher mean $\Sigma$ DDT. However, t-tests did not show any significant differences between male and female babies within villages for $\Sigma$ DDT, p,p'-DDT, p,p'-DDE, p,p'-DDD and o,p'-DDT. Fig. 2F shows the $\Sigma$ DDT levels in multipara whole milk stratified according to male and female infants, per DDT-sprayed village. Multipara males received milk with higher mean $\Sigma D D T$ in every village. However, the differences were not significant (Manguzi $\mathrm{p}=0.0994$; Mseleni $\mathrm{p}=0.1649$; Dididi $\mathrm{p}=0.4652$; t-tests). Nor were there significant differences for the individual compounds. However, male infants drink $10 \%$ more milk than female infants (Michaelsen et al., 1994). Increasing the DDT concentrations by $10 \%$ for male infants reduced the differences for daily intakes between primipara genders, but for multipara infants, the differences increased (t-tests between multipara male and female infants from Manguzi provided a $\mathrm{p}=0.0581$, for Mseleni $\mathrm{p}=0.0949$, and for Dididi, $\mathrm{p}=0.2875$ ).

Because mothers have infants of both sexes, regressions to investigate the possible influence of gender on DDT in breast milk can only be done using primipara data. The only logical independent variable is CDBF (effectively the age of the infant at time of sampling). The best-fitting model was linear regression (Fig.2G). Slopes for both genders was not significantly different from zero (male $\mathrm{p}=0.9901$; female $\mathrm{p}=0.0633$ ). Slopes were equal $(p=0.2957)$ as well as elevations $(p=0.2785)$. 


\subsection{Other observations}

In milk from DDT-sprayed villages, \%DDT varied over a wide range in primipara milk, tapering off towards an intermediate percentage with increasing parity (Fig. 2H). Regression analysis showed no association between \%mf and parity (data not shown). A nonlinear regression could not be fitted.

\section{Discussion}

\subsection{Maternal and infant parameters}

Mean maternal primipara and multipara ages, infant ages, parity, and \%mf were the same between villages (section 3.1). Except for IRS with DDT, we consider the four villages essentially equivalent for maternal and infant variables.

\subsection{Effect of location}

Gwaliweni had significantly lower levels of $\Sigma$ DDT, p,p'-DDT, p,p'-DDE, p,p'-DDD and o,p'-DDT than the DDT-sprayed villages. Manguzi, Mseleni, and Dididi, respectively, had $\Sigma$ DDT about 10-13, 7-8, and 6-7 times higher than the reference village, depending on whole milk or milk fat calculations. Manguzi milk had significantly higher $\Sigma$ DDT levels than Mseleni but not Dididi. Manguzi also had significantly higher levels of \%DDT (section 3.2). In DDT-sprayed homes and homesteads, IRS-applied DDT is the major source of DDT in humans (Sereda et al., 2009; Van Dyk et al., 2010). Van Dyk et al. (2010) showed multiple routes of human uptake in DDT-sprayed homesteads. Bouwman et al. (1990a; 1994) showed changes in levels of DDT in breast milk and serum were directly attributable to IRS (Bouwman et al., 2011).

Manguzi and Mseleni were sprayed almost on the same date, seven months before sample collection. The slight difference in timing is highly unlikely to have caused these significant differences in DDT levels in breast milk from these two towns. The significantly higher levels of DDT and \%DDT in Manguzi breast milk, and the intermediate levels of DDT in Dididi (section 3.2) that was treated only two months prior to sampling, suggests that factors other than timing of IRS. Such factors may be operational (e.g. how DDT is prepared, application methods, pre- and post-treatment procedures, etc.), structural (e.g. types of wall, ventilation, etc.), and cultural (e.g. human behaviours that would affect exposure, such as time spent indoors, sweeping, etc.). Future identification of such factors could suggest ways in which to reduce exposure, and thereby risk to mothers and infants.

\subsection{Exposure and risk}

Table 1 and Fig. 2A shows that breastfeeding mothers from DDT-sprayed villages had levels of DDT significantly exceeding the MRL for DDT (section 3.3). The mean $\Sigma$ DDT in Manguzi primipara milk exceeds the MRL 45 times; the highest measured $\mathrm{DDDT}$ (from Mseleni) was 99 times higher than the MRL. Levels of DDT in milk is closely associated with DDT in maternal blood, indicating hazard to the mother, as well as exposure of reproductive organs and foetus (the health implications are discussed, inter alia, by Longnecker et al., 2001; Eskenazi et al., 2006; Eskenazi et al., 2009; Bornman et al., 2010; Bouwman et al., 2011). These exceedances show that the maternal burden of DDT is cause for concern. 
The PTDI is also exceeded by infants in all three DDT-sprayed villages (Table 1, Fig.2B, and section 3.3). The mean $\Sigma$ DDT for Manguzi primipara milk exceeds the PTDI 14 times, and 310 times for the maximum $\Sigma$ DDT from Mseleni. Considered together with the very long periods of breastfeeding practiced (Table 1, Fig.2C, Fig. 2D, and section 3.3), a considerable amount of DDT will be transferred to the infant via breast milk as was shown elsewhere (Bouwman et al., 1992; Gyalpo et al., In press). Exposure to DDT over a lifetime is therefore likely to be the greatest during foetal and postnatal development, periods likely to be sensitive to chemical harm. It is especially the first-born infants that will be exposed to higher $\Sigma$ DDT levels; therefore experiencing greater risk when compared with their sibs. Research conducted in the same region as Dididi identified DDT-associated effects on male urogenital parameters and reduction of retinol binding protein (Aneck-Hahn et al., 2007; De Jager et al., 2009; Bornman et al., 2010; Delport et al., 2011).

\subsection{Duration of lactation}

There is no indication that the high mean levels of DDT in breast milk had any effect the on duration of lactation (MDBFI) of the mothers in the three DDT-sprayed villages, as there was no difference compared to the reference village (Fig. 2C, and section 3.4). The levels reported here are the highest yet used to investigate the effect of DDT on duration of lactation that we could find (inter alia Rogan and Gladen, 1985; Gladen and Rogan, 1995; Kostyniak et al., 1999; Weldon et al., 2006; Cupul-Uicab et al., 2008).

Fig. 2D shows the effect of cumulative breastfeeding on $\Sigma D D T$ in breast milk independent of parity. A quick reduction with a half-life of 287 days (section 3.4) indicates depuration from a high initial level, and then reaching a plateau. Interestingly, the half-life is also about half of the MDBF (Table 1), emphasising that the bulk of elimination is during breastfeeding the firstborn. Tao et al. (2008) also plotted the same variables and found a halflife of approximately 450 days, but $\Sigma$ DDT levels were lower by an order of magnitude. A one-phase decay model is appropriate, as the rate of change is proportional to the concentration of the chemical.

It would be easy to misinterpret Fig. 2D as indicating that a higher 5 DDT level is associated with a shorter lactation time (effectively switching $\mathrm{X}$ and $\mathrm{Y}$-axes). Reduction in $\Sigma$ DDT levels is caused by lactation as is evident from Fig. 2D. The long MDBFIs by mothers from both the DDT-sprayed villages and the reference village shows no discernible effect on duration of lactation at high or low concentrations.

\subsection{Infant gender and levels of DDT}

The finding by Powe et al. (2010) that male infants receive breast milk with a $25 \%$ greater energy content than female infants, prompted us to investigate the possible involvement of gender with $\Sigma$ DDT levels. Since milk fat makes up a significant proportion of the energy component of breast milk (Nommsen et al., 1991), and organochlorine pesticides associate with the triglycerides in the fat globules of the milk (Hugunin and Bradley, 1971), we hypothesised that DDT levels in milk of mothers breastfeeding baby boys might also be greater. However, sugars and protein also contribute towards energy content and the statistical analyses can therefore only be done on whole milk.

Fig. 2E and 2F show consistent patterns, but not proof, of possible infant gender involvement with maternal levels of DDT. [Fig.2E and 2F shows means and standard deviations, but geometric means and medians show the same patterns.] Primipara female infants received higher mean $\Sigma$ DDT levels in two DDT-sprayed villages, but the differences were not significant (Fig. 2E). Multipara male infants received higher mean $\Sigma$ DDT levels in 
breast milk in every DDT-sprayed village (Fig. 2F); again, the difference was not significant. Incorporating a 10\% increase in levels due to higher breast milk consumption by male infants (Michaelsen et al., 1994) somewhat improved the significance, but caution should be applied. MRLs and PTDIs would mirror this pattern as these metrics are based on whole milk. In Fig. $2 \mathrm{G}$, the regression for primipara female infants was close to deviating from zero at $\mathrm{p}=0.0633$, indicating that the levels in breast mild received by female infants may decline while staying essentially constant $(\mathrm{p}=0.9901)$ for male infants; again there were no statistical differences in gender elimination kinetics.

A number of studies investigated the infant gender differences of pollutants in blood of children. Female umbilical blood from Singapore had higher $\beta-\mathrm{HCH}$, but lower p,p'-DDT and p,p'-DDE than males (not significant) (Tan et al., 2009). For children aged 0-11 years from China, no differences were found between genders (Chen et al., 2010). Female cord serum from Menorca, Spain, had marginally higher levels of HCB and p,p'-DDE than males, but not for PCBs, again no significant differences (Grimalt et al., 2010). None of these studies investigated parity as a confounder.

Hooper et al. (1997) investigated but found no gender effects on pollutants in breast milk from Kazakhstan. No effect of infant gender on pollutant levels in breast milk from mothers from New York State was found (Jackson et al., 2010). Parity, maternal age, or infant gender was found not to be related to PCBs in breast milk from Poznan, Poland (Skrbic et al., 2010). PCBs, p,p'-DDT and p,p'-DDE in breast milk from mothers from North Carolina were not related to infant gender. Parity had no effect or was not reported in these studies.

Our findings are only suggestive of an involvement of gender on levels of DDT in breast milk. The only case that can be made from our data is for higher levels found for primipara female infants in two separate villages (Fig.2E), and consistently higher levels for multipara male infants from all three villages (Fig. 2F). The switch from relatively higher DDT levels in primipara females to relatively higher DDT levels in multipara male infants could be explained by a slightly faster elimination of DDT via breast milk for female infants, or the maintenance of relatively constant levels in breast milk received by male infants (Fig. $2 \mathrm{G})$. However, further research is required.

We cannot explain the phenomenon that \%DDT in DDT-treated villages tapered off towards an intermediate percentage with increasing parity (Fig $2 \mathrm{H}$ ). To our knowledge, it has not been reported previously.

\section{Conclusions and recommendations}

We have previously argued for a Total Homestead Environment approach to investigate exposure and uptake routes in a domestic IRS setting (Van Dyk et al., 2010). The DDT levels in breast milk differ between villages and we have highlighted possible governing factors. Investigating these factors should be further explored and would be instructive as to how exposures to DDT might be reduced. The need for such a comprehensive reduction in exposure is amply illustrated by the exceedances of the MRLs and PTDIs in the three DDT-sprayed villages.

Very high levels of DDT did not affect duration of lactation when compared with the reference village. The endocrine disrupting effects of DDT and its metabolites did not influence duration of lactation that is potentially susceptible to hormone disruption. This is indeed a positive finding as infant nutrition is maintained for many months in poor rural communities.

The underlying mechanisms of how infant gender would affect energy content of breast milk (Powe et al., 2010) needs further investigation of the possibility that the gender of 
the breastfeeding infant may affect the content of DDT or any other pollutants in breast milk for that matter. If so, infant gender should be included in future studies as a classification variable as it may affect risk assessment.

In 1986/87, a breast milk sample was collected that until now had the highest $\Sigma$ DDT level yet reported in South Africa (2.7 mg/l wm and $59 \mathrm{mg} / \mathrm{kg} \mathrm{mf}$ ) (Bouwman et al., 1990b). Now, 24 years later, it is disconcerting that the highest $\Sigma$ DDT level in breast milk yet measured from South Africa (5.2 mg/l wm and $140 \mathrm{mg} / \mathrm{kg} \mathrm{mf}$; Table 1) was found in a breast milk sample collected about $60 \mathrm{~km}$ away from the previous highest $\Sigma$ DDT. Despite numerous scientific assessments recommending that safe and sustainable alternatives to DDT should be urgently investigated and deployed (De Jager et al., 2006; De Jager et al., 2009; Eskenazi et al., 2009; Bornman et al., 2010; Bouwman et al., 2011), a relatively affluent African country is in a position to do much more to reduce exposures or to move away from DDT. It must be acknowledged however, that a previous attempt to switch from DDT to pyrethroids failed (Hargreaves et al., 2003; Maharaj et al., 2005), and that the expectations of proof of safety and sustainability of alternatives have probably increased due to that failure. Added to the concerns of health effects of DDT also comes the concerns associated with pyrethroids (Bouwman et al., 2006; Bouwman and Kylin, 2009). The current malaria prevention measures are very effective (Craig et al., 2004; Gerritsen et al., 2008), but a reduction in DDT exposure is urgently needed, apart from the need to find suitable, safe and sustainable alternatives.

Acknowledgements We thank Dr Cobus van Dyk and Dr Irene Barnhoorn, the Research Support Staff in Thohoyandou, Christa Smit and Lilla Primrose from the Pesticide Analytical Laboratory, Plant Protection Research Institute of the Agricultural Research Council for analysis, and Ephraim Malinga for technical assistance and field work. We also thank KwaZulu-Natal Department of Health (particularly CD Maoela and Korea Gumedi), and personnel from the Manguzi, Mseleni, and Mosvold hospitals and the Bhekabantu, Kwandaba, Oqondweni, Tshongwe, and Gwaliweni clinics. Funding for this project was provided by the Swedish / South African bilateral research agreement, the National Research Foundation of South Africa, the Swedish International Development Cooperation Agency, and the Swedish Research Council. The funding sources did not restrict the authors' freedom to design, conduct, interpret, or publish research.

\section{References}

Aneck-Hahn, N.H., Schulenburg, G.W., Bornman, M.S., Farias, P., De Jager, C., 2007. Impaired semen quality associated with environmental DDT exposure in young men living in a malaria area in the Limpopo Province, South Africa. Journal of Andrology 28, 423-434.

Bornman, R., De Jager, C., Worku, Z., Farias, P., Reif, S., 2010. DDT and urogenital malformations in newborn boys in a malarial area. British Journal of Urology International 106, 405-410.

Bouwman, H., Becker, P.J., Cooppan, R.M., Reinecke, A.J., 1992. Transfer of DDT used in malaria control to infants via breast milk. Bulletin of the World Health Organization 70, 241-250.

Bouwman, H., Becker, P.J., Schutte, C.H.J., 1994. Malaria control and longitudinal changes in levels of DDT and its metabolites in human serum from Kwazulu. Bulletin of the World Health Organization 72, 921-930. 
Bouwman, H., Cooppan, R.M., Reinecke, A.J., Becker, P.J., 1990a. Levels of DDT and metabolites in breast milk from Kwa-Zulu mothers after DDT application for malaria control. Bulletin of the World Health Organization 88, 761-768.

Bouwman, H., and Kylin, H., 2009. Malaria control insecticide residues in breast milk: The need to consider infant health risks. Environmental Health Perspectives 117, 1477-1480.

Bouwman, H., Reinecke, A.J., Cooppan, R.M., Becker, P.J., 1990b. Factors affecting levels of DDT and metabolites in human breast milk from KwaZulu. Journal of Toxicology and Environmental Health. 31, 93-115.

Bouwman, H., Sereda, B.L., Meinhardt, H.R., 2006. Simultaneous presence of DDT and pyrethroid residues in human breast milk from a malaria endemic area in South Africa. Environmental Pollution 144, 902-917.

Bouwman, H., van den Berg, H., Kylin, H., 2011. DDT and malaria prevention: Addressing the paradox. Environmental Health Perspectives 119, 744-747.

Cao, L.L., Yan, C.H., Yu, X.D., Tian, Y., Zhao, L., Liu, J.X., Shen, X.M., 2011. Relationship between serum concentrations of polychlorinated biphenyls and organochlorine pesticides and dietary habits of pregnant women in Shanghai. Science of the Total Environment 409, 2997-3002.

Cerna, M., Bencko, V., Brabec, M., Smid, J., Krskova, A., Jech, L., 2010. Exposure assessment of breast-fed infants in the Czech Republic to indicator PCBs and selected chlorinated pesticides: Area-related differences. Chemosphere 78, 160-168.

Chen, C., Chen, J.W., Zhao, H.X., Xie, Q., Yin, Z.Q., Ge, L.K., 2010. Levels and patterns of polybrominated diphenyl ethers in children's plasma from Dalian, China. Environment International 36, 163-167.

Chikuni, O., Skare, J.U., Nyazema, N., Polder, A., 1991. Residues of organochlorine pesticides in human milk from mothers living in the greater Harare area of Zimbabwe. Central African Journal of Medicine 37, 136-141.

Cohn, B.A., 2011. Developmental and environmental origins of breast cancer: DDT as a case study. Reproductive Toxicology 31, 302-311.

Craig, H.H., Kleinschmidt, J.B., Nawn, J.B., le Sueur, D., Sharp, B.L., 2004. Exploring 30 years of malaria case data in KwaZulu-Natal, South Africa: Part 1. The impact of climatic factors. Tropical Medicine \& International Health 9, 1247-1257.

Cupul-Uicab, L.A., Gladen, B.C., Hernandez-Avila, M., Weber, J.P., Longnecker, M.P., 2008. DDE, a degradation product of DDT, and duration of lactation in a highly exposed area of Mexico. Environmental Health Perspectives 116, 179-183.

Darnerud, P.O., Lignell, S., Glynn, A., Aune, M., Tornkvist, A., Stridsberg, M., 2010. POP levels in breast milk and maternal serum and thyroid hormone levels in mother-child pairs from Uppsala, Sweden. Environment International 36, 180-187.

De Jager, C., Aneck-Hahn, N.H., Bornman, M.S., Farias, P., Leter, G., Eleuteri, P., Rescia, M., Spano, M., 2009. Sperm chromatin integrity in DDT-exposed young men living in a malaria area in the Limpopo Province, South Africa. Human Reproduction 24, 24292438.

De Jager, C., Farias, P., Barraza-Villarreal, A., Avila, M.H., Ayotte, P., Dewailly, E., Dombrowski, C., Rousseau, F., Sanchez, V.D., Bailey, J.L., 2006. Reduced seminal parameters associated with environmental DDT exposure and p,p '-DDE concentrations in men in Chiapas, Mexico: A cross-sectional study. Journal of Andrology 27, 16-27.

Delport, R., Bornman, R., MacIntyre, U.E., Oosthuizen, N.M., Becker, P.J., Aneck-Hahn, N.H., De Jager, C., 2011. Changes in retinol-binding protein concentrations and thyroid homeostasis with nonoccupational exposure to DDT. Environmental Health Perspectives 119, 647-651. 
Eskenazi, B., Marks, A.R., Bradman, A., Fenster, L., Johnson, C., Barr, D.B., Jewell, N.P., 2006. In utero exposure to dichlorophenyltrichloroethane (DDT) and dichlorodiphenyldichloroethylene (DDE) and neurodevelopment among young Mexican American children. Pediatrics 118, 233-241.

Eskenazi, B., Chevrier, J., Rosas, L.G., Anderson, H.A., Bornman, M.S., Bouwman, H., Chen, A.M., Cohn, B.A., De Jager, C., Henshel, D.S., Leipzig, F., Leipzig, J.S., Lorenz, E.C., Snedeker, S.M., Stapleton, D., 2009. The Pine River Statement: Human health consequences of DDT use. Environmental Health Perspectives 117, 1359-1367.

FAO \& WHO, 2005 Joint meeting of the panel of experts on pesticide residues. www.who.int/ipcs/publications/jmpr/en/

Fromberg, A., Granby, K., Hojgard, A., Fagt, S., Larsen, J.C., 2011. Estimation of dietary intake of PCB and organochlorine pesticides for children and adults. Food Chemistry 125, $1179-1187$.

Gascon, M., Vrijheid, M., Martinez, D., Forns, J., Grimalt, J.O., Torrent, M., Sunyer, J., 2011. Effects of pre and postnatal exposure to low levels of polybromodiphenyl ethers on neurodevelopment and thyroid hormone levels at 4 years of age. Environment International 37, 605-611.

Gerritsen, A.A.M., Kruger, P., van der Loeff, M.F.S., Grobusch, M.P., 2008. Malaria incidence in Limpopo Province, South Africa, 1998-2007. Malaria Journal 7.

Gladen, B.C., and Rogan, W.J., 1995. DDE and shortened duration of lactation in a northern Mexican town. American Journal of Public Health 85, 504-508.

Glynn, A., Lignell, S., Darnerud, P.O., Aune, M., Ankarberg, E.H., Bergdahl, I.A., Barregard, L., Bensryd, I., 2011. Regional differences in levels of chlorinated and brominated pollutants in mother's milk from primiparous women in Sweden. Environment International 37, 71-79.

Grimalt, J.O., Carrizo, D., Gari, M., Font-Ribera, L., Ribas-Fito, N., Torrent, M., Sunyer, J., 2010. An evaluation of the sexual differences in the accumulation of organochlorine compounds in children at birth and at the age of 4 years. Environmental Research 110, 244-250.

Gyalpo, T., Fritsche, L., Bouwman, H., Bornman, R., Scheringer, M., Hungerbüler, K., In press. Estimation of human body concentrations of DDT from indoor residual spraying for malaria control. Environmental Pollution.

Hargreaves, K., Hunt, R.H., Brooke, B.D., Mthembu, J., Weeto, M.M., Awolola, T.S., Coetzee, M., 2003. Anopheles arabiensis and An. quadriannulatus resistance to DDT in South Africa. Medical and Veterinary Entomology 17, 417-422.

Harris, C.A., Woolridge, M.W., Hay, A.W.M., 2001. Factors affecting the transfer of organochlorine pesticide residues to breastmilk. Chemosphere 43, 243-256.

Hooper, K., Petreas, M.X., She, J., Visita, P., Winkler, J., McKinney, M., Mok, M., Sy, F., Garcha, J., Gill, M., Stephens, R.D., Semenova, G., Sharmanov, T., Chuvakova, T., 1997. Analysis of breast milk to assess exposure to chlorinated contaminants in Kazakstan: PCBs and organochlorine pesticides in Southern Kazakstan. Environmental Health Perspectives 105, 1250-1254.

Hugunin, A.G., and Bradley, J., 1971. Distribution of organochlorine pesticides among some milk components. Journal of Dairy Science 54, 355-359.

Jackson, L.W., Lynch, C.D., Kostyniak, P.J., McGuinness, B.M., Louis, G.M.B., 2010. Prenatal and postnatal exposure to polychlorinated biphenyls and child size at 24 months of age. Reproductive Toxicology 29, 25-31.

Jusko, T.A., Koepsell, T.D., Baker, R.J., Greenfield, T.A., Willman, E.J., Charles, M.J., Teplin, S.W., Checkoway, H., Hertz-Picciotto, I., 2006. Maternal DDT exposure in relation to fetal growth and 5-year growth. Epidemiology 6, 692-700. 
Kostyniak, P.J., Stinson, C., Greizerstein, H.B., Vena, J., Buck, G., Mendola, P., 1999. Relation of Lake Ontario fish consumption, lifetime lactation, and parity to breast milk polychrlobiphenyl and pesticide concentrations. Environmental Research Section A 80, S166-S174.

Laug, E.P., Kunze, F.M., Pricket, C.S., 1951. Occurrence of DDT in human fat and milk. American Medical Association Archives of Industrial Hygiene and Occupational Medicine 3, 245-246.

Longnecker, M.P., Klebanoff, M.A., Zhou, H., Brock, J.W., 2001. Association between maternal serum concentration of the DDT metabolite DDE and preterm and small-forgestational-age babies at birth. Lancet 358, 110-114.

Mackay, D., Shiu, W.Y., Ma, K-C., Lee, S.C., 2006. Physical-chemical properties and environmental fate of organic chemicals. $2^{\text {nd }}$ Ed. CRC Press, Boca Raton.

Maharaj, R., Mthembu, D.J., Sharp, B.L., 2005. Impact of DDT re-introduction on malaria transmission in KwaZulu-Natal. South African Medical Journal 95, 871-874.

Michaelsen, K.F., Larsen, P.S., Thomsen, B.L., Samuelson, G., 1994. The Copenhagen cohort study on infant nutrition and growth - Duration of breast-feeding and influencing factors. Acta Paediatrica 83, 565-571.

Mishra, K., and Sharma, R.C., 2011. Assessment of organochlorine pesticides in human milk and risk exposure to infants from North-East India. Science of the Total Environment 409, 4939-4949.

Nommsen, L.A., Lovelady, C.A., Heinig, M.J., Lonnerdal, B., Dewey, K.G., 1991. Determinants of energy, protein, lipid, and lactose concentrations in human-milk during the 1St 12 Months of lactation - the Darling Study. American Journal of Clinical Nutrition 53, 457-465.

Okonkwo, J.O., Mutshatshi, T.N., Botha, B., Agyei, N., 2008. DDT, DDE and DDD in human milk from South Africa. Bulletin of Environmental Contamination and Toxicology 81, 348-354.

Powe, C.E., Knott, C.D., Conklin-Brittain, N., 2010. Infant sex predicts breast milk energy content. American Journal of Human Biology 22, 50-54.

Ribas-Fitó, N., Torrent, M., Carrizo, D., Muñoz-Ortiz, L., Júlvez, J., Grimalt, J.O., Sunyer, J., 2006. In utero exposure to background concentrations of DDT and cognitive functioning among preschoolers. American Journal of Epidemiology 164, 955-962.

Rogan, W.J., and Gladen, B.C., 1985. Study of human lactation for effects of environmental contaminants: The North Carolina Breast Milk and Formula Project and some other ideas. Environmental Health Perspectives 60, 215-221.

Rogan, W.J., Gladen, B.C., McKinney, J.D., Carreras, N., Hardy, P., Thullen, J., Tingelstad, J., Tully, M., 1987. Polychlorinated biphenyls (PCBs) and dichlorodiphenyl dichloroethene (DDE) in human milk: Effects on growth, morbidity, and duration of lactation. American Journal of Public Health 77, 1294-1297.

Sereda, B., Bouwman, H., Kylin, H., 2009. Comparing water, bovine milk, and indoor residual spraying as possible sources of DDT and pyrethroid residues in breast milk. Journal of Toxicology and Environmental Health - Part A 72, 842-851.

Skrbic, B., Szyrwinska, K., Durisic-Mladenovic, N., Nowicki, P., Lulek, J., 2010. Principal component analysis of indicator PCB profiles in breast milk from Poland. Environment International 36, 862-872.

Stockholm Convention. 2012. www.pops.int

Tan, J., Loganath, A., Chong, Y.S., Obbard, J.P., 2009. Exposure to persistent organic pollutants in utero and related maternal characteristics on birth outcomes: A multivariate data analysis approach. Chemosphere 74, 428-433. 
Tao, S., Yu, Y.X., Liu, W.X., Wang, X.J., Cao, J., Li, B.G., Lu, X.X., Wong, M.H., 2008. Validation of dietary intake of dichlorodiphenyltrichloroethane and metabolites in two populations from Beijing and Shenyang, China, based on the residuals in human milk. Environmental Science \& Technology 42, 7709-7714.

van den Berg, H., 2009. Global status of DDT and its alternatives for use in vector control to prevent disease. Environmental Health Perspectives 117, 1656-1663.

Van Dyk, J.C., Bouwman, H., Barnhoorn, I.E.J., Bornman, M.S., 2010. DDT contamination from indoor residual spraying for malaria control. Science of the Total Environment 408, 2745-2752.

Weldon, R.H., Webster, M., Harley, K., Bradman, A., Fenster, L., Barr, D.B., Jewell, N.P., Holland, N., Eskenazi, B., 2006. Exposure to persistent organic pollutants and duration of lactation in Mexican-American mothers. Epidemiology 17, S193.

Wetterauer, B., Ricking, M., Otte, J., Hallale, A., Rastall, A., Erdinger, L., Schwarzbauer, J., Braunbeck, T., Hollert, H., 2012. Toxicity, dioxin-like activities, and endocrine effects of DDT metabolites - DDA, DDMU, DDMS, and DDCN. Environmental Science and Pollution Research 19, 403-415.

WHO. 2007. Malaria elimination: A field manual for low and moderate endemic countries. World Health Organization, Geneva, pp. 1-85.

WHO. 2011a. DDT in indoor residual spraying: Human health aspects. Environmental Health Criteria 241. World Health Organization, Geneva, pp. 1-309.

WHO. 2011b. World malaria report 2011. World Health Organization, Geneva, pp. 1-246. 


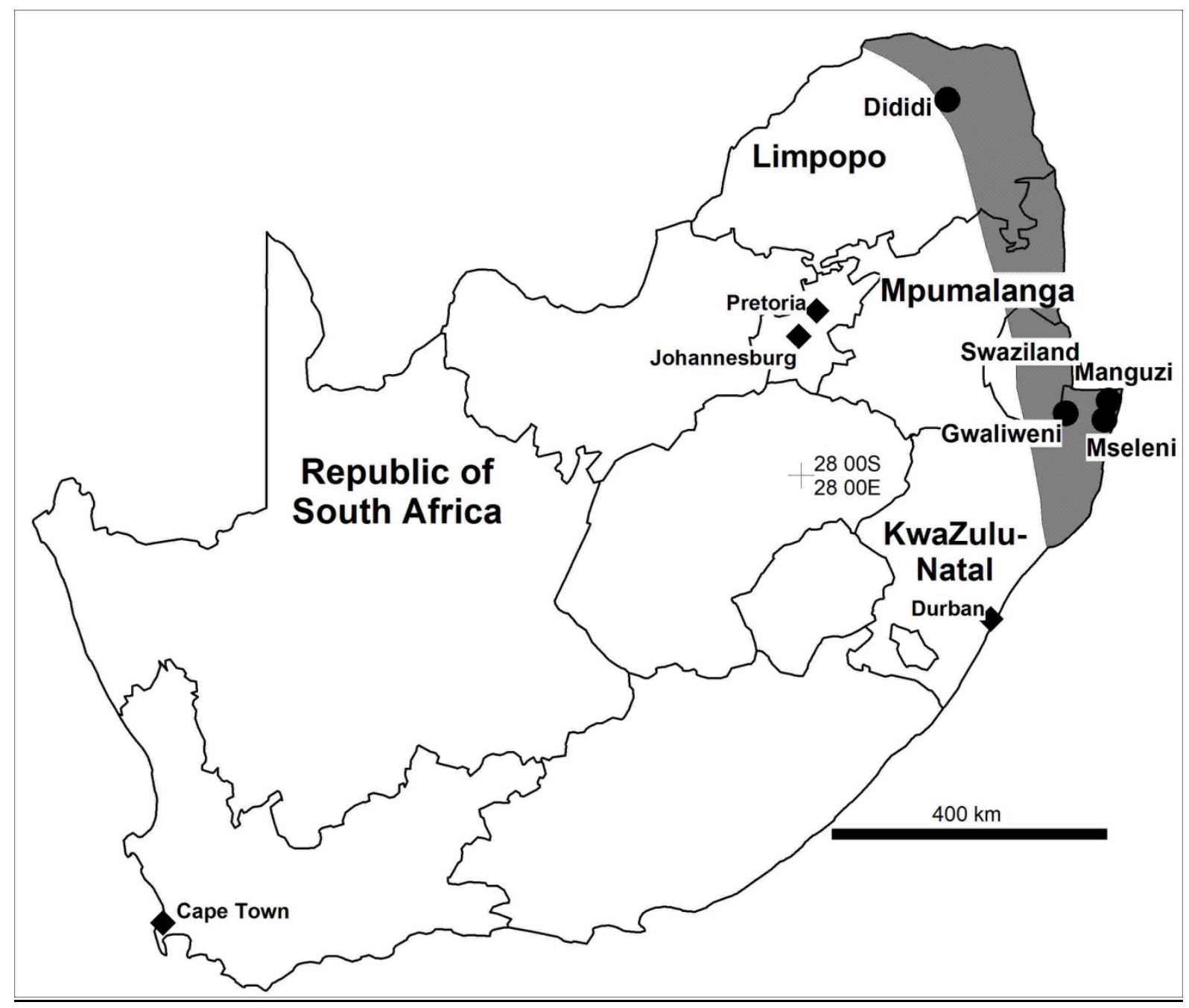

Fig.1. Localities of villages where breast milk was collected. Shaded area indicated malaria endemic areas. 

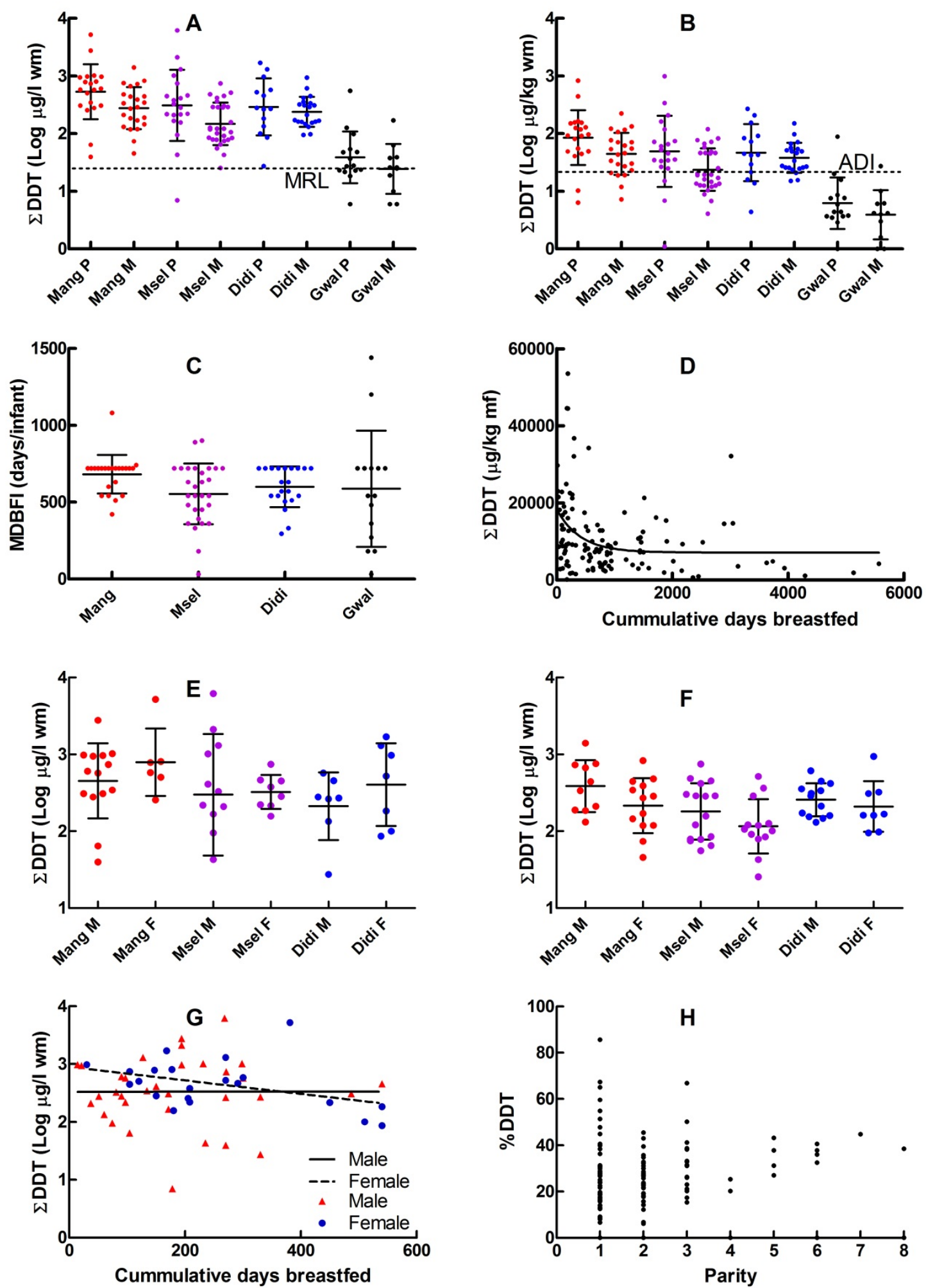

Fig. 2. DDT-related variables in breast milk for four towns; Mang = Manguzi, Msel = Mseleni, Didi = Dididi, Gwal = Gwaliweni. (A) Whole milk $\Sigma$ DDT levels in breast milk from four towns, stratified according to parity. Maximum Residue Limit (MRL) is indicated. $\mathrm{P}=$ primipara, $\mathrm{M}=$ multipara. (B) Infant intake of $\Sigma \mathrm{DDT}$ from four towns, stratified according to parity. $\mathrm{P}=$ primipara, $\mathrm{M}=$ multipara. $(\mathrm{C})$ Mean days breastfed per infant (MDBFI) per town. (D) $\Sigma$ DDT in breast milk fat plotted against cumulative days breastfed. (E) $\Sigma$ DDT in whole 
milk received by primipara infants in the three DDT-sprayed towns. $\mathrm{M}=$ males, $\mathrm{F}=$ females. (F) $\Sigma$ DDT in whole milk received by multipara infants in the three DDT-sprayed towns. (G) Linear regressions of $\Sigma$ DDT received by primipara male and female infants against cumulative days breast fed (effectively infant age). (H) Scatterplot of \%DDT in breast milk per parity. In some instances, high concentration dots were excluded from plots although they were included in the statistics. 
Table 1 Variables relating to subjects and DDT parameters from the four villages.

\begin{tabular}{|c|c|c|c|c|c|c|c|c|c|c|c|c|c|c|c|c|}
\hline & & \multicolumn{7}{|c|}{ Manguzi primipara (n=20) KZN DDT-sprayed } & \multicolumn{7}{|c|}{ Manguzi multipara (n=23) KZN DDT-sprayed } & \multirow{2}{*}{$\begin{array}{r}\text { Combined } \\
\text { Mean }\end{array}$} \\
\hline & & Mean & Median & SD & Min & Max & NPos & $\%$ Pos & Mean & Median & SD & Min & Max & NPos & $\%$ Pos & \\
\hline M Age & Years & 19.20 & 19 & 2.35 & 15 & 23 & & & 29 & 29 & 6.28 & 20 & 45 & & & 24.3 \\
\hline Inf Age & Days & 183 & 174 & 118 & 14 & 487 & & & 151 & 134 & 130 & 7 & 464 & & & 166 \\
\hline $\begin{array}{l}\text { BF } \\
\text { completed }\end{array}$ & Days & & & & & & & & 681 & 720 & 126 & 420 & 1080 & & & $2.2^{*}$ \\
\hline ppDDT wm & $\mu \mathrm{g} / 1$ & 380 & 190 & 630 & 15 & 2700 & 20 & 100 & 140 & 89 & 140 & 13 & 610 & 23 & 100 & 250 \\
\hline ppDDE wm & $\mu \mathrm{g} / 1$ & 380 & 340 & 300 & 24 & 1100 & 20 & 10 & 170 & 120 & 136 & 24 & 540 & 23 & 100 & 260 \\
\hline ppDDD wm & $\mu \mathrm{g} / 1$ & 118 & 49 & 200 & 10 & 880 & 18 & 90 & 65 & 41 & 63 & $<\mathrm{LOQ}$ & 260 & 18 & 78 & 91 \\
\hline opDDT wm & $\mu \mathrm{g} / 1$ & 61 & 30 & 110 & $<\mathrm{LOQ}$ & 410 & 12 & 60 & 26 & 19 & 25 & $<\mathrm{LOQ}$ & 110 & 15 & 65 & 38 \\
\hline$\Sigma$ DDT wm & $\mu \mathrm{g} / 1$ & 900 & 590 & 1200 & 40 & 5200 & 20 & 100 & 380 & 290 & 320 & 46 & 1400 & 23 & 100 & 630 \\
\hline$\%$ DDT & & 35 & 31 & 14 & 14 & 65 & 20 & 10 & 37 & 38 & 10 & 20 & 67 & 23 & 100 & 35.7 \\
\hline \%Milk fat & $\mu \mathrm{g} / \mathrm{kg}$ & 3.50 & 3.43 & 1.36 & 1.53 & 6.24 & & & 3.40 & 3.55 & 1.55 & 1.08 & 8.27 & & & 3.43 \\
\hline ppDDT mf & $\mu \mathrm{g} / \mathrm{kg}$ & 10000 & 6100 & 1600 & 720 & 74000 & 20 & 100 & 4000 & 3200 & 3200 & 950 & 14000 & 23 & 100 & 6900 \\
\hline ppDDE mf & $\mu \mathrm{g} / \mathrm{kg}$ & 11000 & 9400 & 8000 & 1200 & 310000 & 20 & 10 & 5100 & 3600 & 3700 & 860 & 15000 & 23 & 100 & 7800 \\
\hline ppDDD mf & $\mu \mathrm{g} / \mathrm{kg}$ & 3500 & 1400 & 5600 & 470 & 24000 & 18 & 90 & 2000 & 1200 & 1800 & 170 & 6700 & 18 & 78 & 2700 \\
\hline opDDT mf & $\mu \mathrm{g} / \mathrm{kg}$ & 1700 & 810 & 3100 & 180 & 11000 & 12 & 60 & 820 & 590 & 610 & 330 & 2500 & 15 & 65 & 1200 \\
\hline$\Sigma \mathrm{DDT} \mathrm{mf}$ & $\mu \mathrm{g} / \mathrm{kg}$ & 25000 & 18000 & 31000 & 1900 & 140000 & 20 & 100 & 11000 & 10000 & 82000 & 3100 & 34000 & 23 & 100 & 18000 \\
\hline \multirow[t]{3}{*}{ Daily intake } & $\mu \mathrm{g} / \mathrm{kg} \mathrm{bw}$ & 140 & 95 & 190 & 6.4 & 830 & 20 & 100 & 61 & 46 & 51 & 7.3 & 220 & 23 & 100 & 100 \\
\hline & & & seleni pr & mipara & $n=20) K$ & $\mathrm{ZN} \mathrm{DDT}$ & sprayed & & & seleni mu & tipara (r & $=29) \mathrm{K} 2$ & ZN DDT & sprayed & & Combined \\
\hline & & Mean & Median & SD & Min & Max & NPos & $\%$ Pos & Mean & Median & SD & Min & Max & NPos & $\%$ Pos & Mean \\
\hline M Age & Years & 19 & 18 & 2.27 & 16 & 23 & & & 29 & 27 & 7.21 & 20 & 49 & & & 24.7 \\
\hline Inf Age & Days & 180 & 175 & 96 & 37 & 450 & & & 199 & 178 & 116 & 30 & 494 & & & 191 \\
\hline $\begin{array}{l}\text { BF } \\
\text { completed }\end{array}$ & Days & & & & & & & & 554 & 540 & 199 & 30 & 900 & & & $2.2 *$ \\
\hline ppDDT wm & $\mu \mathrm{g} / 1$ & 190 & 71 & 250 & $<\mathrm{LOQ}$ & 820 & 17 & 85 & 53 & 36 & 53 & $<\mathrm{LOQ}$ & 250 & 25 & 86 & 113 \\
\hline ppDDE wm & $\mu \mathrm{g} / 1$ & 560 & 220 & 1200 & $<\mathrm{LOQ}$ & 5300 & 19 & 95 & 140 & 62 & 130 & 26 & 490 & 29 & 100 & 300 \\
\hline ppDDD wm & $\mu \mathrm{g} / 1$ & 53 & 54 & 26 & $<\mathrm{LOQ}$ & 97 & 15 & 75 & 23 & 23 & 14 & $<\mathrm{LOQ}$ & 56 & 20 & 70 & 36 \\
\hline opDDT wm & $\mu \mathrm{g} / 1$ & 18 & 13 & 16 & $<\mathrm{LOQ}$ & 57 & 9 & 45 & 17 & 8 & 28 & $<\mathrm{LOQ}$ & 110 & 14 & 48 & 17 \\
\hline$\Sigma$ DDT wm & $\mu \mathrm{g} / 1$ & 750 & 310 & 1400 & 7 & 6200 & 20 & 100 & 210 & 120 & 180 & 26 & 750 & 29 & 100 & 430 \\
\hline$\%$ DDT & & 27 & 24 & 15 & 8.6 & 67 & 16 & 80 & 26 & 26 & 8.9 & 6.8 & 45 & 25 & 86 & 22.3 \\
\hline \%Milk fat & $\mu \mathrm{g} / \mathrm{kg}$ & 3.86 & 3.67 & 1.30 & 1.67 & 6.84 & & & 3.54 & 3.53 & 1.25 & 1.31 & 6.70 & & & 3.60 \\
\hline ppDDT mf & $\mu \mathrm{g} / \mathrm{kg}$ & 4600 & 1600 & 5400 & 160 & 16000 & 17 & 85 & 1400 & 1100 & 1100 & 360 & 5600 & 25 & 86 & 2700 \\
\hline ppDDE mf & $\mu \mathrm{g} / \mathrm{kg}$ & 13000 & 6700 & 23000 & 560 & 100000 & 19 & 95 & 3800 & 2600 & 3200 & 680 & 13000 & 29 & 100 & 7400 \\
\hline ppDDD mf & $\mu \mathrm{g} / \mathrm{kg}$ & 1400 & 1200 & 910 & 410 & 4000 & 15 & 75 & 600 & 510 & 320 & 230 & 1400 & 20 & 70 & 940 \\
\hline opDDT mf & $\mu \mathrm{g} / \mathrm{kg}$ & 460 & 330 & 400 & 98 & 1400 & 9 & 45 & 380 & 250 & 400 & 130 & 1700 & 14 & 48 & 410 \\
\hline$\Sigma$ DDT mf & $\mu \mathrm{g} / \mathrm{kg}$ & 17000 & 8800 & 27000 & 160 & 120000 & 20 & 100 & 5700 & 4500 & 4000 & 680 & 17000 & 29 & 100 & 11000 \\
\hline Daily intake & $\mu \mathrm{g} / \mathrm{kg}$ bw & 120 & 49 & 220 & 1.1 & 990 & 20 & 100 & 33 & 19 & 29 & 4.1 & 120 & 29 & 100 & 69 \\
\hline & & & lidi primi & para $(n=$ & 14) $\operatorname{Lim}$ & opo DDT & -spraye & & Dic & idi multip & $\operatorname{ara}(n=2$ & 1) Limp & opo DD' & Г-spraye & & nbined \\
\hline & & Mean & Median & SD & Min & Max & NPos & $\%$ Pos & Mean & Median & SD & Min & Max & NPos & $\%$ Pos & Mean \\
\hline M Age & Years & 19.8 & 20 & 19.79 & 18 & 24 & & & 28.8 & 28 & 4.36 & 23 & 39 & & & 25.2 \\
\hline Inf Age & Days & 303 & 285 & 178 & 30 & 540 & & & 260 & 270 & 152 & 7 & 480 & & & 277 \\
\hline $\begin{array}{l}\text { BF } \\
\text { completed }\end{array}$ & Days & & & & & & & & 600 & 630 & 132 & 294 & 720 & & & $2.1^{*}$ \\
\hline ppDDT wm & $\mu \mathrm{g} / 1$ & 78 & 86 & 44 & 9 & 160 & 11 & 79 & 66 & 60 & 39 & $<\mathrm{LOQ}$ & 160 & 17 & 81 & 71 \\
\hline ppDDE wm & $\mu \mathrm{g} / 1$ & 360 & 200 & 410 & 14 & 1400 & 14 & 100 & 160 & 120 & 100 & 74 & 490 & 21 & 100 & 240 \\
\hline ppDDD wm & $\mu \mathrm{g} / 1$ & 62 & 49 & 32 & $<\mathrm{LOQ}$ & 113 & 11 & 79 & 54 & 40 & 50 & $<\mathrm{LOQ}$ & 240 & 21 & 100 & 57 \\
\hline opDDT wm & $\mu \mathrm{g} / 1$ & 28 & 27 & 16 & $<\mathrm{LOQ}$ & 54 & 8 & 57 & 23 & 27 & 14 & $<\mathrm{LOQ}$ & 42 & 14 & 67 & 25 \\
\hline$\Sigma$ DDT wm & $\mu \mathrm{g} / 1$ & 490 & 275 & 500 & 27 & 1700 & 14 & 100 & 290 & 210 & 200 & 95 & 940 & 21 & 100 & 370 \\
\hline$\% D D T$ & & 21 & 16 & 22 & 6.7 & 86 & 11 & 79 & 21 & 20 & 6.0 & 6.1 & 31 & 17 & 81 & 16.8 \\
\hline \%Milk fat & $\mu \mathrm{g} / \mathrm{kg}$ & 3.54 & 3.53 & 1.25 & 1.31 & 6.69 & & & 4.02 & 3.69 & 1.65 & 1.2 & 8.57 & & & 3.50 \\
\hline ppDDT mf & $\mu \mathrm{g} / \mathrm{kg}$ & 2500 & 2300 & 1800 & 190 & 7000 & 11 & 79 & 1800 & 1600 & 940 & 320 & 3400 & 17 & 81 & 2100 \\
\hline ppDDE mf & $\mu \mathrm{g} / \mathrm{kg}$ & 8200 & 6800 & 6200 & 1200 & 20000 & 14 & 100 & 4400 & 3700 & 2500 & 890 & 9900 & 21 & 100 & 5900 \\
\hline ppDDD mf & $\mu \mathrm{g} / \mathrm{kg}$ & 1700 & 1600 & 920 & 210 & 4000 & 11 & 79 & 1400 & 1000 & 1000 & 260 & 4000 & 21 & 100 & 1500 \\
\hline opDDT mf & $\mu \mathrm{g} / \mathrm{kg}$ & 670 & 670 & 260 & 300 & 1100 & 8 & 57 & 600 & 700 & 380 & 88 & 1000 & 14 & 67 & 630 \\
\hline$\Sigma \mathrm{DDT} \mathrm{mf}$ & $\mu \mathrm{g} / \mathrm{kg}$ & 12000 & 11000 & 7500 & 1600 & 25000 & 14 & 100 & 7800 & 7200 & 4600 & 1100 & 17000 & 21 & 100 & 9500 \\
\hline Daily intake & $\mu \mathrm{g} / \mathrm{kg}$ bw & 78 & 44 & 80 & 4.4 & 270 & 14 & 100 & 46 & 34 & 32 & 15 & 150 & 21 & 100 & 59 \\
\hline & & Gwal & iweni pri & nipara (1 & $\mathrm{n}=20) \mathrm{K} 2$ & $\mathrm{~N}$ non $\mathrm{D}$ & DT-spra & yed & Gwal & weni mul & ipara (n & $=16) \mathrm{KZ}$ & $\mathrm{N}$ non $\mathrm{D}$ & DT-spra & ayed & Combined \\
\hline & & Mean & Median & $\mathrm{SD}$ & Min & Max & NPos & $\%$ Pos & Mean & Median & SD & Min & Max & NPos & $\%$ Pos & Mean \\
\hline M Age & Years & 20.25 & 19 & 4.36 & 16 & 35 & & & 26.6 & 24 & 6.36 & 20 & 39 & & & 23.2 \\
\hline Inf Age & Days & 240 & 198 & 172 & 81 & 734 & & & 127 & 104 & 106 & 14 & 358 & & & 188 \\
\hline & & & & & & & & & & & & & & & & \\
\hline completed & Days & & & & & & & & 588 & 540 & 378 & 30 & 1440 & & & $2.0^{*}$ \\
\hline ppDDT wm & $\mu \mathrm{g} / 1$ & 49 & 28 & 29 & $<\mathrm{LOQ}$ & 134 & 4 & 20 & 32 & 26 & 9.2 & $<\mathrm{LOQ}$ & 50 & 3 & 15 & 42 \\
\hline ppDDE wm & $\mu \mathrm{g} / 1$ & 52 & 27 & 79 & $<\mathrm{LOQ}$ & 330 & 15 & 75 & 26 & 25 & 21 & $<\mathrm{LOQ}$ & 74 & 11 & 55 & 41 \\
\hline ppDDD wm & $\mu \mathrm{g} / 1$ & 36 & 23 & 35 & $<\mathrm{LOQ}$ & 87 & 4 & 20 & 29 & & & $<\mathrm{LOQ}$ & 29 & 1 & 6 & 35 \\
\hline opDDT wm & $\mu \mathrm{g} / 1$ & 6.0 & 6.0 & 1.0 & $<\mathrm{LOQ}$ & 6.0 & 2 & 10 & 18 & 18 & & $<\mathrm{LOQ}$ & & 1 & 6 & 10 \\
\hline$\Sigma$ DDT wm & $\mu \mathrm{g} / 1$ & 76 & 28 & 140 & $<\mathrm{LOQ}$ & 560 & 15 & 75 & 39 & 26 & 47 & $<\mathrm{LOQ}$ & 171 & 11 & 55 & 60 \\
\hline$\% D D T$ & & 23 & 26 & 12 & 6.1 & 34 & 4.0 & 20 & 49 & 41 & 25 & 29 & 77 & 3 & 15 & 9.2 \\
\hline \%Milk fat & $\mu \mathrm{g} / \mathrm{kg}$ & 4.32 & 4.03 & 1.5 & 2.03 & 8.84 & & & 3.44 & 3.09 & 1.26 & 1.56 & 5.95 & & & 3.64 \\
\hline ppDDT mf & $\mu \mathrm{g} / \mathrm{kg}$ & 1100 & 780 & 1100 & 88 & 2700 & 4 & 20 & 880 & 740 & 430 & 530 & 1400 & 3 & 15 & 1000 \\
\hline ppDDE mf & $\mu \mathrm{g} / \mathrm{kg}$ & 1100 & 640 & 1600 & 150 & 6600 & 15 & 75 & 750 & 580 & 660 & 190 & 2000 & 11 & 55 & 950 \\
\hline ppDDD mf & $\mu \mathrm{g} / \mathrm{kg}$ & 780 & 550 & 680 & 270 & 1700 & 4 & 20 & 790 & & & $<\mathrm{LOQ}$ & 790 & 1 & 6 & 780 \\
\hline opDDT mf & $\mu \mathrm{g} / \mathrm{kg}$ & 120 & & & $<\mathrm{LOQ}$ & 120 & 2 & 10 & 490 & & & $<\mathrm{LOQ}$ & 490 & 1 & 6 & 250 \\
\hline$\Sigma \mathrm{DDT} \mathrm{mf}$ & $\mu \mathrm{g} / \mathrm{kg}$ & 1600 & 710 & 2700 & $<\mathrm{LOQ}$ & 11000 & 15 & 75 & 1100 & 660 & 1300 & $<\mathrm{LOQ}$ & 4700 & 11 & 55 & 1400 \\
\hline Daily intake & $\mu \mathrm{g} / \mathrm{kg}$ bw & 12 & 4.4 & 22 & $<\mathrm{LOQ}$ & 89 & 15 & 75 & 6.3 & 4.2 & 7.5 & $<\mathrm{LOQ}$ & 27 & 11 & 55 & 9.7 \\
\hline
\end{tabular}

*=mean parity 